\title{
A contribuição do PIBID para repensar o currículo dos cursos de licenciaturas
}

Carlos Soares Barbosa (UERJ)

\section{Resumo}

O objetivo do presente artigo é analisar a contribuição das experiências do Programa Institucional de Bolsa de Iniciação à Docência (PIBID) na reformulação dos cursos de licenciaturas em nosso país, haja vista a necessidade de se repensar a formação de professores da educação básica diante das demandas dos novos tempos. Fundamenta-se na pesquisa sobre os conhecimentos construídos no subprojeto 'Saberes de Jovens e Adultos e Saberes Docentes', pertencente ao referido programa e desenvolvido desde 2013 por estudantes do curso de Licenciatura em Pedagogia da UERJ/Maracanã em uma escola de Educação de Jovens e Adultos do município do Rio de Janeiro. A pesquisa foi realizada entre os anos de 2014 e 2015 e utilizou-se de grupo focal, análise dos relatórios produzidos pelos licenciandos-bolsistas e observação de suas atuações na escola, além de entrevistas com os professores da escola parceira. Os resultados apontam as potencialidades e limitações da inserção dos futuros professores no cotidiano da escola desde o início da graduação, como está previsto nas novas diretrizes nacionais para a formação da educação básica (Resolução CNE n. 02/2015).

Palavras-chaves: Pibid; Formação de Professor; Reforma Curricular.

\begin{abstract}
The aim of the present article is to analyze the contribution of the experiences of the Institutional Program of Initiation Scholarship to Teaching (PIBID) in the reformulation of undergraduate courses in our country, given the need to rethink the education of basic education teachers in the new times. This article is based on the knowledge builted in the subproject 'Knowledge of Youth and Adults and Knowledge Teachers', belonging to this program and developed since 2013 by Pedagogy students in a school of Youth Education and Adults of the municipality of Rio de Janeiro. The research was carried out between the years 2014 and 2015 and a focus group was used, analysis of the reports produced by the licenciandos-grantees and observation of their performances in the school, as well as interviews with the teachers of the partner school. The results point to the potentialities and limitations of the inclusion of future teachers in the daily life of the school from the beginning of the graduation, in accordance with the new national guidelines for the formation of basic education.
\end{abstract}

Keywords: Pibid; teacher training; curricular reform

\section{Introdução}

Qual a contribuição das experiências do Programa Institucional de Bolsa de Iniciação à Docência (PIBID) na reformulação dos cursos de licenciaturas? O que o programa sinaliza de novo para a formação dos futuros docentes? Essas questões nasceram, em um primeiro momento, do interesse em promover a interlocução entre os aprendizados construídos durante os encontros de docentes e discentes, ocorridos com o propósito de se pensar a reformulação do curso de Licenciatura em Pedagogia da Universidade do Estado do Rio de Janeiro (UERJ), campus Maracanã, entre os anos de 2016 e 2017, e os conhecimentos produzidos por um grupo de estudantes do referido curso, bolsistas do subprojeto "Saberes de Jovens e Adultos e Saberes Docentes", pertencente ao Pibid. Trata-se de discussão em torno da dinâmica do currículo em ambas as experiências, entendendo por currículo o conjunto das experiências de aprendizagens que contribuem para 
a formação das identidades dos educandos. Desse modo, pensar a reformulação de qualquer currículo nos impõe, a priori, refletir sobre o sujeito que pretendemos formar e os princípios que fundamentam o percurso necessário para tal objetivo. Essas foram as preocupações iniciais dos grupos de trabalhos formados por docentes e discentes, dadas as muitas mediações ideológicas, políticas, econômicas e sociais presentes na discussão a respeito da (re)formulação curricular, seja na educação básica e/ou no ensino superior. Isso significa afirmar que o processo de construção e reformulação curricular não se faz isento de disputas políticas e ideológicas, já que a discussão sobre currículo é, per si, não só a discussão sobre o tipo de ser humano e de profissional que queremos formar, mas também o tipo de sociedade que pretendemos colaborar em construir.

De certo, a mudança do milênio e o avanço das novas tecnologias da informação e da comunicação trouxeram consigo não só a instituição de novos valores e de modos de convivência e sociabilidade entre os diferentes povos, mas também fomentaram a necessidade de se repensar as concepções epistemológicas, os procedimentos metodológicos e a própria pesquisa, de modo a ampliar os olhares sobre os sujeitos e a considerar as múltiplas experiências, vozes e sentidos presentes no próprio conceito de formação. Foi com este propósito de acompanhar as demandas produzidas pelos novos tempos que diretrizes curriculares nacionais para a formação da educação básica têm sido elaboradas desde o início do novo milênio, haja vista os Pareceres CNE/CP n. 9 e n. 28, de 2001, que imprimiram as universidades de todo país a reverem seus cursos de licenciaturas.

Considerando que a mudança na educação básica e o compromisso com a escola pública de qualidade para todos também passam pela mudança de concepções nos cursos de formação inicial e continuada de professores que a ela se destinarão, recentemente, ainda no governo Dilma Roussef, por meio da Resolução CNE/CP n. 02, de 1 de julho de 2015 , foram instituídas as diretrizes curriculares nacionais para a formação inicial em nível superior (cursos de licenciatura, cursos de formação pedagógica para graduados e cursos de segunda licenciatura) e para a formação continuada. Ao analisar as referidas diretrizes, verifica-se a apropriação das reflexões teóricas acumuladas no campo cientifico da formação docente, bem como das exitosas experiências sistematizadas por inúmeras Instituições de Ensino Superior (IES), com base nos projetos desenvolvidos no âmbito do Pibid e relatados nos encontros regionais/nacionais.

Financiado pela Coordenação de Aperfeiçoamento de Pessoal de Nível Superior (CAPES), o Pibid foi posto em prática a partir de 2009 e faz parte do conjunto de 26 iniciativas que compõem os "programas do MEC voltados para a Formação de Professores" (BRASIL/MEC/CAPES, 2010). Objetivando o aperfeiçoamento e a valorização da formação de professores para a educação básica, o programa concede bolsas a alunos de licenciatura participantes de projetos de iniciação à docência, desenvolvidos por IES em parceria com escolas de educação básica da rede pública de ensino, com o propósito de

elevar a qualidade da formação inicial de professores nos cursos de licenciatura, promovendo a integração entre educação superior e educação básica; contribuir para a articulação entre teoria e prática necessárias à formação dos docentes, elevando a qualidade das ações acadêmicas nos cursos de licenciatura (CAPES, 2010).

Em particular, o Pibid UERJ, por meio do projeto institucional "Saber escolar e formação docente na educação básica", estabeleceu parcerias com cerca de 45 escolas municipais e estaduais, nos municípios do Rio de Janeiro, São Gonçalo, Itaboraí, Resende e Nova Friburgo, desenvolvendo projetos, nas diversas disciplinas do currículo escolar, articuladores de diálogos e trocas de experiências entre graduandos, professores universitários e professores da educação básica, realizando de forma complementar e planejada estudos teóricos, projetos pedagógicos e experimentações didáticas (UERJ, 2016). Este artigo está fundamentado na pesquisa sobre os conhecimentos construídos no subprojeto "Saberes de Jovens e Adultos e Saberes Docentes", desenvolvido no curso de Licenciatura em Pedagogia da UERJ/Maracanã, desde 2013. Conta com a participação de 12 bolsistas, distribuídos em duas escolas da rede municipal de ensino do Rio de Janeiro, localizadas na Zona Norte da cidade, que ofertam classes de alfabetização e do ensino fundamental $\left(1^{\circ} \mathrm{e} 2^{\circ}\right.$ segmentos) no horário noturno, na modalidade da Educação de Jovens e Adultos. As reflexões aqui tecidas fundamentam-se na análise dos relatórios produzidos nos anos de 2014 e 2015 pelos licenciandos-bolsistas de uma das escolas parceiras, em conjunto com a observação de suas atuações no cotidiano escolar e de entrevistas de roteiros semi-estruturados realizadas com os professores da escola pesquisada. Diante do atual contexto vivido na UERJ de reformulação curricular dos cursos de licenciaturas, os resultados dos dados 
visam somar-se ao esforço de repensar as licenciaturas existentes no país, de modo geral. Para isso, em um primeiro momento, tecemos um breve estudo da arte no campo da formação docente, a fim de demonstrar que as propostas contidas no Pibid e nas atuais diretrizes (Resolução CNE n. 02/2015) são demandas - há tempos- reivindicadas pelos educadores e pesquisadores do campo.

\section{Formação docente: breve estudo da arte}

O campo científico da formação do professor tem apresentado um volume expressivo de produções nos últimos anos. Segundo Pimenta (2005), podemos organizar as tendências investigativas contemporâneas na área de formação de professores em três grupos: 1) a importância das investigações em situações concretas, configurando o que se tem denominado de epistemologia da prática, valorizando os processos de construção de conhecimentos de professores; 2) a importância da concepção professor-reflexivo e suas possibilidades e limites nos contextos escolares; 3) a importância dos saberes, identidade e da profissão e da profissionalidade docente, apontando para a questão do professor pesquisador.

Os objetivos e a forma como o Pibid se estrutura convergem com o conjunto dessas demandas reivindicadas pelos estudiosos do campo. O programa foi criado em 2009, em um contexto marcado tanto pela ausência de uma política pública que tratasse especificamente da formação docente, quanto pela descontextualização dos conhecimentos na maioria dos cursos de licenciaturas, apresentados sem muita relação com o trabalho docente concreto, embora as Diretrizes Nacionais para a Formação da Educação Básica, de 2001, já ressaltassem a indissociabilidade entre teoria e prática. O estudo realizado por Malucelli (2001) demonstra que a polarização entre o fazer e o pensar se fazia (e ainda se faz) presente em muitos cursos de licenciaturas; fato que se expressa na estruturação curricular na qual pesquisa, ensino e prática ainda se configuram como polos separados. Para a autora, a estrutura curricular de grande parte dos cursos de licenciaturas ainda se faz de forma tradicional, agrupando as disciplinas em disciplinas de conteúdo, disciplinas pedagógicas e disciplinas chamadas integradoras (ou de ponte com a prática).

Essa segmentação e hierarquização das disciplinas, em que primeiro se aprende "o que" e "como fazer" (disciplinas teóricas e disciplinas ligadas à prática) para depois se fazer o que foi aprendido, é alvo de críticas dos pesquisadores e estudiosos ao longo dos últimos 20 anos. No final do século passado, Libâneo e Pimenta (1999: 267) argumentavam que 'é preciso integrar os conteúdos das disciplinas em situações da prática, que coloquem problemas aos futuros professores e lhes possibilitem enfrentar soluções. [O que] significa ter a prática ao longo do curso [...]'. Nesta mesma direção, Nóvoa (2003) defende uma formação que proporcione situações que possibilitem a reflexão e a tomada de consciência das limitações sociais, culturais e ideológicas da própria profissão docente. Para isso, argumenta que os futuros professores devem ser inseridos na realidade escolar durante todo o processo de formação, uma vez que determinadas especificidades da profissão só serão adquiridas com a convivência na escola. Sem desconsiderar o papel desempenhado pela universidade, ressalta que a bagagem essencial de um professor adquire-se na escola, através da experiência e da reflexão sobre a experiência; reflexão esta que não acontece ao acaso, mas que tem regras e métodos próprios.

Em 2008, a pesquisa realizada pela Fundação Carlos Chagas revelou que as disciplinas com conhecimentos específicos sobre a docência (voltadas à prática e às didáticas específicas) representavam, no máximo, 30\% da carga horária das graduações (RATIER, 2010). Essa segmentação favorece que se mantenha no imaginário social a representação da universidade como espaço de elaboração e transmissão da teoria - "que não dá conta da prática", pois "na prática a teoria é outra" - e da escola como espaço da execução de tarefas rotineiras, sem muita reflexão. O resultado desse processo é uma formação descolada da prática; professores pouco instrumentalizados teoricamente para pensar os problemas reais da sua prática e pouco instigados a refletir os desafios dela originados.

Isto ocorre porque, de modo geral, a inserção dos futuros professores na realidade escolar ocorre nos períodos finais dos cursos de licenciaturas, viabilizada pelas disciplinas de estágio e de prática de ensino. Essas disciplinas tendem a privilegiar a observação da "prática" com pouca possibilidade de participação 
dos futuros professores no planejamento e na execução das atividades. Assim conduzidas e sem recorrer ao apoio conceitual e teórico da investigação científica, este modelo proporciona o risco da reprodução de vícios, preconceitos, mitos e obstáculos epistemológicos acumulados na prática empírica, como salientam Monteiro (2002) e Pimenta (1997). Ao mesmo tempo, não capacita os licenciandos a desvendar a complexidade da escola, por não levá-los a conhecer e a refletir sobre o modo como tal realidade foi gerada. Esta é uma realidade que o Pibid visa superar ao definir que os projetos, ao inserir os licenciandos no cotidiano de escolas da rede pública de educação, devem proporcionar-lhes 'oportunidades de criação e participação em experiências metodológicas, tecnológicas e práticas docentes de caráter inovador e interdisciplinar que busquem a superação de problemas identificados no processo de ensino-aprendizagem' (Brasil, Capes, 2010).

A necessidade de se estabelecer um ambiente de diálogo entre os profissionais da educação básica e a comunidade acadêmica se intensifica com o desenvolvimento de pesquisas voltadas para a constituição do processo formativo no exercício da ação docente. No movimento denominado de "epistemologia da prática" (TARDIF, 2000), pesquisadores e estudiosos têm defendido a necessidade de valorizar o professor como detentores de saberes, enquanto sujeitos do processo ensino-aprendizagem, capazes de buscar, com auxílio da teoria, as respostas para os desafios que se apresentam no decorrer da sua prática. É ela [a prática] que sinaliza as questões que a teoria ajuda a interpretar e a propor alternativas, que, por sua vez, se transformam em novas práticas, tornando-se ponto de partida de novas indagações. Para isso, faz-se necessário que o professor se constitua em pesquisador de sua própria prática, o que Schön (1997) denomina de "professor reflexivo", entendendo a prática como espaço de produção de saberes específicos, fruto do movimento de reflexão crítica e contínua da própria prática por parte dos docentes (TARDIF, 2004).

Entretanto, quais as condições necessárias para que o professor realize a reflexão crítica e contínua da sua própria prática? Como é possível que o futuro docente se constitua em um "professor reflexivo" de sua própria prática, sem que a sua formação se organize sob o mesmo enfoque reflexivo e possua identidade crítica?

A busca por respostas a estes questionamentos tem fortalecido a necessidade de se estreitar a relação entre universidade-escola e o desejo de que a formação e a prática educativa sejam conduzidas na perspectiva da práxis. Uma formação na perspectiva da práxis, aqui entendida como unidade teórico-prática, supõe uma prática reflexiva que possibilite aprender a praticar a docência no próprio percurso da prática docente, tendo em vista que, como argumenta Fortuna (2007), a realidade escolar possibilita aos futuros professores um exercício pessoal de revisão e de exploração dos saberes adquiridos no próprio percurso de sua formação, mas pensando-os a partir de questões postas pelo real concreto da situação escolar.

É nesta perspectiva que se fundamenta epistemologicamente o Parecer CNE/CP n. 2/2015, ao tratar a formação dos profissionais do magistério como um direito, e, portanto, alçada ao nível da política pública, entendendo a formação inicial e continuada como um continuum, garantido pela institucionalização de um projeto de formação a ser ofertado aos profissionais das redes. Esta forma de conceber a formação ressalta o papel estruturante da prática profissional e a importância estratégica da pesquisa, concebendo como ato formador o trabalho pedagógico do professor. Essa concepção de formação definida pelas novas diretrizes implica o desenvolvimento de cursos e processos promovidos em articulação com o sistema de educação básica, o que inclui não apenas necessidades de formação docente, mas a inserção dos estudantes de licenciatura nas instituições de educação básica da rede pública de ensino - espaço privilegiado da práxis docente.

Por esta razão, entendemos a contribuição das experiências e os conhecimentos produzidos no âmbito do Pibid para se repensar os cursos de licenciaturas, sobretudo por inserir os licenciandos na realidade escolar na perspectiva de professores-pesquisadores, reconhecendo o protagonismo das escolas públicas de educação básica nos processos de formação inicial para o magistério, considerando seus professores como coformadores dos futuros docentes. Para isso, o programa garante tempos-espaços de pesquisa e de formação contínua, que ocorrem tanto na escola, na interação com os professores da unidade escolar e a supervisora do subprojeto (também professora da escola), quanto na universidade, através das disciplinas cursadas e dos encontros semanais para estudos com a coordenadora (professora do curso de licenciatura). 
a experiência do Pibid, reivindicam a construção de um currículo que promova a inserção dos futuros docentes no cotidiano da escola desde o início de sua formação, por entender a escola como espaço de construção de novas idéias, de pesquisa, e não apenas de execução de teorias. Não se trata, no entanto, de uma assertiva linear e mecânica, mas construída através de conflitos e disputas de idéias, de alegrias e decepções, como veremos a seguir.

\section{O PIBID como instrumento de inserção dos futuros professores na escola}

Embora o intercâmbio entre a formação de professores e o desenvolvimento de projetos educacionais nas escolas seja uma tendência da política educacional mundial, esta articulação ainda é muito frágil nos cursos de formação docente em nosso país. Todavia, entre os objetivos do Pibid estão:

[...] IV - inserir os licenciandos no cotidiano de escolas da rede pública de educação, proporcionandoIhes oportunidade de criação e participação em experiências metodológicas, tecnológicas e práticas docentes de caráter inovador e interdisciplinar que busquem a superação de problemas identificados no processo de ensino-aprendizagem; [...] VI - contribuir para a articulação entre teoria e prática necessária à formação dos docentes elevando a qualidade das ações acadêmicas nos cursos de licenciaturas (BRASIL, Decreto n. 7.219, de 24 de junho de 2010).

A valorização da prática enquanto momento importante na formação do professor se faz presente nos aparatos legais há bastante tempo, a exemplo da resolução CNE/CP n. 2/2002, que instituiu 400 horas de prática como componente curricular, vivenciadas ao longo da graduação, e 400 horas de estágio curricular supervisionado a partir do início da segunda metade do curso, do total de carga horária mínima de 2.800 horas. Esta proposta e as atuais diretrizes intentam que a prática se constitua em um espaço de reflexão crítica e de pesquisa desde a fase inicial da formação, reconhecendo, porém, que "não é a prática que é formadora, mas sim a reflexão sobre a prática. É a capacidade de refletirmos e analisarmos” (Nóvoa, 2007: 16) que faz a diferença ante os modelos de formação de professor vigentes em boa parte das Instituições de Ensino Superior. Afinal, "não há ensino sem pesquisa e pesquisa sem ensino. Esses quefazeres se encontram um no corpo do outro”, como ressalta Freire (1996: 29).

Nos encontros institucionais e nacionais do Pibid, verifica-se a consensualidade entre os diferentes atores de que o programa contribui para a valorização do magistério, amplia a formação inicial dos futuros professores e imprime outras dinâmicas, tanto na escola quanto na universidade. Ao mesmo tempo em que influencia na produção de ideias, nos modos de agir e nas práticas na escola e nos profissionais que lá trabalham, retroalimenta e contribui para a superação da formação fragmentada oferecida nas universidades, por ampliar e oportunizar a articulação entre os licenciandos e professores da escola básica, como afirma Silva (2011). Conforme constatamos em nossa pesquisa, trata-se de um movimento dialético e pouco natural, no início, devido a pouca institucionalização de diálogo entre escola-universidade. Daí entende-se que nos primeiros meses de desenvolvimento do subprojeto a maioria dos professores da escola pesquisada acreditar que os bolsistas não tinham muito com que lhes contribuir, como expressam os depoimentos abaixo:

na universidade se aprende muitas teorias que não ajudam o professor a enfrentar os desafios da sala de aula, porque só se aprende a ser professor no dia a dia da sala de aula (Educador $C, 2^{\circ}$ segmento, 2014).

a leitura de algum autor não vai fazer eu melhorar a minha prática ou de qualquer outro professor. Isso ocorre muito mais pela experiência, pela própria prática, do que pela leitura das teorias (Educadora B, $1{ }^{\circ}$ segmento, 2014).

Todavia, sendo a escola um espaço dinâmico e contraditório, expressão de sínteses provisórias decorrentes de arranjos e conflitos existentes em seu interior, há também grupo de professores que reconhece a importância de ações como o Pibid para a formação docente. Para a professora do $1^{\circ}$ segmento do ensino fundamental,

o Pibid possibilita os futuros professores conhecerem a realidade da escola pública e, ao mesmo tempo, a sua presença ajuda a nós, professor, com as tarefas, e nos estimula a pensar em novas metodologias, em novas atividades (Educadora A, $1^{\circ}$ segmento, 2014). 
Durante a realização da pesquisa, acompanhamos duas ações desenvolvidas pelos bolsistas com os alunos das seis turmas de EJA existentes na escola (uma classe de alfabetização, uma do $1^{\circ}$ segmento e quatro do $2^{\circ}$ segmento do ensino fundamental). No primeiro semestre, foi realizada uma roda de conversas sobre "Os movimentos sociais e o Estado de direitos: a organização e a luta popular na garantia efetiva dos direitos existentes e na criação de novos direitos"; ação bem acolhida pelos alunos e professores. No segundo semestre, cada bolsista realizou uma atividade de intervenção pedagógica, planejada em conjunto com um professor da escola. Segundo a coordenadora e o supervisor do Subprojeto, a ideia era de que professores e bolsistas, ao planejarem juntos, pudessem refletir sobre as metodologias e as práticas condizentes aos sujeitos da EJA.

$\mathrm{Na}$ avaliação dos licenciandos-bolsistas, tais atividades fizeram superar alguns receios e compreender a imprevisibilidade da sala de aula, uma vez que a prática foi o ponto de partida e de chegada da ação planejada. Por ser o subprojeto pesquisado voltado às pessoas jovens, adultas e idosas, os licenciandos-bolsistas perceberam os variados desafios enfrentados por esta modalidade da educação básica, tanto em relação às condições físicas e estruturais, quanto de ordem político-pedagógica, ao constatarem a pouca reflexão por parte dos professores e gestores em relação às especificidades da EJA e a diversidade dos sujeitos atendidos, apesar dos espaços-tempos destinados aos estudos/planejamento dos docentes. Para um dos licenciandos -bolsistas, esta é uma situação grave, já que 'nem todos os docentes são preparados para trabalhar com as questões emergentes da EJA’ (Bolsista A, entrevista realizada em 10/12/2014).

Ainda que os relatos de experiências apresentados nos encontros regionais e nacionais ressaltem que a inserção dos licenciandos na realidade escolar influencia na produção de ideias, nos modos de agir e nas práticas da escola e dos profissionais que lá trabalham, reafirmamos não ser este um movimento natural. Na escola pesquisada, verificamos que a ressignificação das práticas pedagógicas dos professores é a dimensão da formação potencializada pelo Pibid que apresenta maior dificuldade. Foram poucos os que abriram espaço para as propostas provocadoras e provocativas que os licencando-bolsistas tentaram empreender. Algumas mediações foram consideradas para a pouca abertura do corpo docente para as atividades de reflexão de suas próprias práticas, a saber: as precárias condições de trabalho, o cansaço dos professores que atuam na EJA no horário noturno (para todos os docentes da escola pesquisada se tratava da terceira jornada de trabalho) e a ausência de sistematização de estudos coletivos na escola, embora parte da carga horária seja reservada a este fim.

Por meio da análise dos relatórios e do grupo focal realizado com os licenciandos-bolsistas, constatamos que a prática na escola torna o conhecimento dos saberes da docência muito mais significativo e sinaliza um caminho viável para a formação do "professor-pesquisador", por fomentá-los a conhecer, pensar e renovar a prática. Assim, em vez de meras observações de práticas bem sucedidas para fins de reprodução futura, o Pibid possibilita que os sujeitos em formação realizem um exercício de revisão e de exploração dos saberes adquiridos no próprio percurso de sua formação, a partir da realidade complexa da escola. Resulta desse processo uma melhor relação entre teoria e prática, o que demonstra a necessidade de os cursos de licenciaturas proporcionarem a inserção cada vez mais precoce dos futuros professores no cotidiano escolar, dandolhes o suporte teórico para que esta se constitua em uma imersão reflexiva.

\section{Considerações Finais}

As narrativas dos licenciandos-bolsistas demonstram que, mais do que um recurso metodológico, o contato com a realidade escolar, desde o início da formação, além de possibilitar a compreensão da complexidade que envolve a prática pedagógica e a construção de uma identidade profissional compromissada com a educação pública e com os cidadãos atendidos também fortalece o futuro professor, na medida em que o faz se sentir um pouco mais preparado para enfrentar as imprevisibilidades e incertezas com quais se defrontam no dia a dia da sua prática, sobretudo, quando se faz acompanhado de um fecundo diálogo com a teoria. Este não é um movimento fácil e natural, em face do frouxo diálogo historicamente instituído entre universidade-escola e a utilização instrumental e pragmática da escola por parte de pesquisadores acadêmicos. Exige compromisso de ambas as partes, por entender que a valorização dos profissionais do magistério e a formação docente - inicial e continuada - são elementos importantes, entre muitos outros, para a melhoria da qualidade da educação pública. 
As experiências construídas no Pibid - ao valorizar os saberes docentes e instituir os professores da educação básica como coformadores dos futuros professores, conferindo centralidade à pesquisa -, nos apontam as potencialidades a serem dinamizadas e as fragilidades a serem superadas pelas novas diretrizes curriculares nacionais para a formação inicial em nível superior e para a formação continuada. Embora não tenhamos a pretensão de generalizar os achados da pesquisa por entendermos que cada experiência do Pibid em cada escola parceira é um caso único, histórico e socialmente construído pelos sujeitos envolvidos, ainda assim, afirmamos a necessidade dos cursos de licenciaturas considerarem a escola e as vivências aí estabelecidas como espaço de construção de conhecimentos, de identidade profissional e, portanto, espaço também legítimo de formação de futuros professores. É um caminho viável para se romper a dicotomia secular entre o fazer e o pensar, entre a teoria e a prática.

\section{Referências Bibliográficas}

BRASIL, CNE, RESOLUÇÃO CNE/CP 2/2015. Diário Oficial da União, Brasília, 01 de julho de 2015.

BRASIL. Decreto 7.219, de 24 de junho de 2010. Dispõe sobre o Programa Institucional de Bolsa de Iniciação à Docência - PIBID e dá outras providências. <wWw.capes.gov.br/images/stories/download/diversos/DecretoPIBID_240610.pdf>,12/02/2014.

BRASIL, CNE, RESOLUÇÃO CNE/CP 2/2002. Diário Oficial da União, Brasília, 4 de março de 2002.

BRASIL, CNE, PARECER CNE/CP, 9/2001. Diário Oficial da União, Brasília, 18 de janeiro de 2002. <http://portal.mec.gov.br/cne/ arquivos/pdf/009.pdf>, 23/08/2016.

FORTUNA, M. L. de A. A prática do ensino e os estágios supervisionados no cotidiano da escola: uma aposta na formação do professor-pesquisador. In: FONTOURA, H. A. (org.). Diálogos em formação de professores: pesquisas e práticas. Rio de Janeiro/ Niterói: Intertexto, 2007.

FREIRE, P. Pedagogia da autonomia: Saberes necessários à prática educativa. São Paulo: Paz e Terra, 1996.

FURTADO; C. M.; PEREIRA, L. H. F. A formação docente na licenciatura e no exercício da docência. IV Mostra de Pesquisa da PósGraduação Programa de Pós-Graduação em Educação, Faculdade de Educação, PUC-RS, 2009.

LIBÂNEO, J. C.; PIMENTA, S. G. Formação de profissionais da educação: visão crítica e perspectiva de mudança. Educação e Sociedade, Campinas, v. 20, n.68, p. 239-277, dez. 1999.

MALUCELLI, V. M, B. Análise crítica da formação dos profissionais da educação: revisando a licenciatura em Biologia. Revista Diálogo Educacional - v. 2 - n.4 - p.139-152 - jul./dez. 2001

MONTEIRO, A. M. A prática de ensino e a produção de saberes na escola. In: CANDAU, V. (org.). Didática, currículo e saberes escolares. Rio de Janeiro: DP\&A, 2002, 2a ed.

NÓVOA, A. Desafios do trabalho do professor no mundo contemporâneo. Palestra ministrada no Sindicato dos Professores de São Paulo (SINPRO-SP), em 2007. <http://www.sinpro.org.br/arquivos/novoalivreto_novoa.pdf>,10/04/2012.

Novas disposições dos professores: A escola como lugar da formação; Adaptação de uma conferência proferida no II Congresso de Educação do Marista de Salvador (Baía, Brasil), em Julho de 2003. <http://repositorio.ul.pt/bitstream/10451/685/1/21205_ce.pdf>, 16/09/2014.

PIMENTA, S. G. Professor-Pesquisador: mitos e possibilidades. Contrapontos - volume 5 - n. 1 - p. $09-22$ - Itajaí, jan./abr. 2005.

O estágio na formação de professores: unidade teoria e prática? 3. ed. São Paulo: Cortez, 1997.

RATIER, R. A fragilidade de cursos de Pedagogia e de licenciaturas no Brasil. Revista Nova Escola. Edição 231, Abril, 2010. <http://revistaescola.abril.com.br/formacao/fragilidade-cursos-pedagogia-licenciaturas-brasil-graduacao-formacao-docente-546805. shtm>, 25/07/2015.

UERJ, Universidade do Estado do Rio de Janeiro. Política de formação docente da UERJ - inicial e continuada. Sub-reitoria de graduação. Comissão consultiva ad hoc; Outubro, 2016.

SHÖN, D. A. Formar professores como profissionais reflexivos. In: NÓVOA, A. (Org.). Os professores e sua formação. Lisboa: Dom Quixote, 1997. p. 77-92.

TARDIF, M. Saberes docentes e formação profissional. Petrópolis: Vozes, 2004.

2000.

Saberes profissionais de professores e conhecimentos universitários. Revista Brasileira de Educação. n.19, jan/abr. 